\title{
O desespero no presente: uma interpretação de "Crônica do Amor Louco"
}

\section{Ricardo Musse*}

\begin{abstract}
Resumo
O autor analisa o filme Crônica do amor louco na perspectiva de uma crítica do presente histórico e de sua indigência se comparado às utopias contraculturais.

Palavras-chave: contracultura, cinema, geração beat.
\end{abstract}

A escolha de Charles Bukowski, privilegiando certo tipo de literatura e comportamento estreitamente entrelaçados, não é casual no filme de Marco Ferreri, Crônica do Amor Louco (Tales of Ordinary Madness). Mas tampouco é, como muito se afirmou, determinante. Essa deliberação certamente não se prende a um juízo de valor estético que superestime a obra de Bukowski, digamos, diante do núcleo original da geração "beat", cujo projeto ele, ao mesmo tempo, continua e dilui. Nem tampouco configura uma rendição ao "mundo sórdido", pervertido e autocomplacente, geralmente atribuído a esse escritor. Com certeza, Marco Ferreri valoriza mais a solidão intrínseca e o horizonte de marginalização social aí delineado que o individualismo um tanto quanto esteticizante da geração de Kerouac, Ginsberg, Corso, Ferlinghetti e Burroughs. Mas parece patente que a preferência por Bukowski prende-se a outra ordem de coisas.

O filme não pretende fazer história ou crítica literária, não que isso esteja vedado ao cinema, ao contrário, é o mais comum, sob o disfarce de "reconstrução" biográfica ou histórica de um autor ou corrente artística. Mas, na melhor tradição do cinema de esquerda, propõe-se

* Ricardo Musse, ex-presidente do cineclube "Antônio das Mortes", é professor no Departamento de Sociologia da USP.

Comun. Inf., v. 5, n. 1/2, p.117-119, jan./dez. 2002 
antes estabelecer um diagnóstico do presente histórico. O fato de esse aspecto principal ter sido, em geral, negligenciado pela recepção de Crônica do Amor Louco talvez resulte do tom um tanto quanto sombrio da análise.

A trajetória da personagem poeta/escritor (Ben Gazzara) encarna (mas também filtra, numa chave predominantemente estética) uma série de questões do mundo contemporâneo.

Na sequêencia inicial, o poeta, logo após louvar o individualismo à americana (superposto aos pequenos ecos da transgressão à francesa e da contracultura italiana) é logrado por uma garota de idade (e identidade) indefinida, que tudo faz para ir a Holywood. Pode-se ver aí uma ironia diante das virtudes desse individualismo, mas também um acerto de contas com os remanescentes de uma finada tradição alternativa, amplificada pela contracultura.

Desistindo da carreira de poeta viajante, o personagem instala-se $\mathrm{em}$ Los Angeles, buscando refúgio na transgressão sexual e na arte, associadas numa mesma unidade contra o convencionalismo da vida familiar. O encontro com Cass (Ornella Mutti) torna-se quase inevitável. Alegoria simultânea da beleza (e da arte) prostituída e da transgressão levada ao extremo (da autoflagelação à morte), Cass representa um ideal estético, cujas conseqüências o poeta conhece de antemão. Tanto assim que procura (não tão bravamente) resistir à sua sedução.

Nesse esforço, submerge no mundo dos excluídos, buscando solidariedade e esperança (apanágio dos desesperados). Aí, a convivência com a impotência social não é tão frustante quanto a demonstrada incapacidade de indignação e revolta. Essa identificação com os excluídos, a busca de um lugar à margem da sociedade para o artista, nasce da rejeição da possibilidade de vender sua força de trabalho. A recusa em ccnceber a prática artística como "trabalho" (num mundo em que ele está associado à reificação), a constatação de que o mundo do trabalho tornou-se um dos pilares da ordem dominante indica a transferência da esperança utópica de uma revolução (operária) para a revolta.

A tensão (fonte do drama) da relação entre o poeta e Cass assenta-se, sobretudo, na impossibilidade dessa convergência momentânea perdurar. Ela o seduz por seu comportamento anti-social, versão atualizada de uma estética modernista que se nutriu da rejeição e destruição das convenções sociais. (o que fornece à estética "punk" da

Comun. Inf., v. 5, n. 1/2, p.117-119, jan./dez. 2002 
personagem seu conteúdo de verdade), tornando de antemão impossível qualquer tentativa de convivência duradoura.

O poeta tampouco tem êxito na tentativa de integração social, configurada na aceitação de um convite para trabalhar em New York. Por mais que a sociedade esteja se tornando permissiva, a ponto de consumir (e até mesmo venerar) a transgressão, vender sua força de trabalho como os demais significa, no mínimo, sucumbir à infecundidade, pois o material da arte não se encontra nos escritórios da indústria cultural ou das universidades. Ele pulsa exclusivamente na vida das ruas.

Eis por que a escolha de Bukowski não é indiferente. A autoconstrução de sua "persona" literária, sua visão de mundo e os temas que aborda se referem mais ao presente que à obra da geração beat (pressupondo-se, aqui, que na personagem, por mais que seja moldada pelo filme, encontrem-se ecos do escritor). Mas, paradoxalmente, sua relevância apóia-se não em sua originalidade, mas em sua capacidade de expressar o geral, ou melhor, o espírito do tempo.

A indigência do presente, ao longo do filme, toma a forma de uma série de aporias. Dito de forma brutal, o filme constata que a contracultura, a utopia de uma revolta generalizada, a boêmia literária, o ideal estético-modernista e os focos centrais de esperança que nortearam os artistas e os intelectuais ao longo das últimas décadas exauriram-se.

\section{Abstract}

The author analyses the movie Crônica do amor louco as a critic of the contemporary moment and its penury if compared to the counter culture utopias.

Keywords: film analysis, counterculture, beat generation.

Comun. Inf., v. 5, n. 1/2, p.117-119, jan./dez. 2002 